Iranian Journal of

Educational

Sociology

\section{Iranian journal of educational Sociology}

(Interdisciplinary Journal of Education)

Available online at: http://www.iase-idje.ir/

Volume 2, Number 2, July 2019

\title{
The relationship between social capital and quality of life with job satisfaction of teachers
}

\author{
Sadegh Ahmadi ${ }^{1 *}$ \\ 1. Undergraduate Student of Primary Education, Farhangian University, Zanjan, Iran.
}

\section{Article history:}

Received date: 20 January 2019

Review date: 25 March 2019

Accepted date: 28 March 2019

\section{Keywords:}

Social Capital, Job Satisfaction, Quality of Life, Teachers

\begin{abstract}
Purpose: The purpose of this study was to investigate the relationship between social capital and quality of life with job satisfaction of teachers.

Methodology: The present study was a descriptive correlational one in terms of purpose and method of data collection. The target population of this study was the teachers of Tehran city in 1998-99. 180 individuals were selected through multistage cluster random sampling. Data were collected using the Gannon Job Satisfaction Questionnaire (1981), Nachapithe and Guchal Social Capital Questionnaire (1998), and the World Health Organization Quality of Life Scale (1996).

Findings: The results showed that social capital and quality of life had a significant positive relationship with teachers' job satisfaction. Also, structural capital, communication capital and cognitive capital and quality of life significantly predicted $48 \%$ of teachers' job satisfaction $(\mathrm{P}<0.05)$.

Conclusion: The results of the study showed that social validity and validity, which are the major components of teachers 'social capital, determine the quality of life and will lead to teachers' job motivation and job satisfaction.
\end{abstract}

\footnotetext{
Please cite this article: Ahmadi S. (2019). The relationship between social capital and quality of life with job satisfaction of teachers, Iranian journal of educational Sociology. 2(2):174-181.
}

* Corresponding Author Email: sadegahmadi76@gmail.com 


\section{Introduction}

Education is the most important social institution derived from the context of society and at the same time constructive and moving and its impact on the development of society is quite tangible (Shirvani Shiri, Norouzi, and Nematollahi, 2019). This system is made up of elements that each of these elements are effective in advancing their goals. Teacher as one of the elements is of special importance in education system (Rezaei Sharif, Karimianpour, Moradi \& Karimayanpour, 2018). Teacher job satisfaction has been one of the issues that has been much dealt with in recent decades (Dicke, Marsh, Parker, Guo, 2019). In order to achieve the goals of any organization, it should be possible for the staff to perform the task in an attractive environment with complete satisfaction and satisfaction in order to achieve the required efficiency and effectiveness (KabatFarr, Cortina, Marchiondo, 2018). Job satisfaction is defined as an enjoyable emotional state that results from the evaluation of one's job or job experience (Robbins, 2001). Job satisfaction is the amount of positive emotions and attitudes that individuals have toward their jobs. When a person says he or she has high job satisfaction, it means that he or she really likes his job, has good feelings about his job and values his job highly (Hardin \& Donaldson, 2014). Consequences of job dissatisfaction include job loss, absenteeism, aggression, illness, and job loss (Judge, Weiss, Kammeyer - Mueller, Hulin, 2017).

Staffing is one of the factors that is very effective in the survival of organizations today and is always considered by the authorities (Schaumberg \& Flynn, 2017). At the same time, each individual seeks a job that satisfies his or her psychological needs in addition to satisfying his / her physical needs (Bellamy, Wang, McGee, Liu, 2019). The success of an organization largely depends on the effort and satisfaction of its employees. It can be said that employees with high morale, creativity and skill have better and higher job satisfaction and this job satisfaction can lead to general health of employees (Hardin \& Donaldson, 2014). Human performance is subject to factors that affect the personal, family, social, and occupational life processes of individuals (Demerouti, Bakker, Leiter, 2014).

The more motivated a teacher is, the more effective he or she can be in the classroom (Collie, Shapka, Perry, 2012). Satisfying psychosocial needs such as credibility, sense of belonging, responsibility and participation, satisfaction of cognitive needs such as challenges, creativity, diverse tasks and, ultimately, a material factor in the group of motivational factors or driving force in the profession (Hagman, 1992, Translated by Goodarzi, 2016). Research in most cultures has shown that the teaching profession is one of the most stressful jobs. As a result, most teachers experience burnout and a decrease in motivation and performance in their jobs (Burić, Penezić \& Sorić, 2017).

Alongside human and economic capital, there is now another capital called social capital (Cheng, Wang, Sigerson, \& Chau, 2019). Social capital, or the spiritual dimension of a community, is a historical legacy that is able to overcome the problems of that community by encouraging individuals to participate in social interaction and move toward economic, political, and economic growth, And so on (Van den Bergh, Schmittmann \& Vermunt, 2017). The concept of social capital was first introduced by sociologists and used in their research. This concept gradually gained the attention of scholars of other disciplines. The concept of social capital reveals the fundamental importance of strong networks, trust-based relationships and partnerships in communities (Halevy, Halali \& Cohen, 2019). Social capital is a set of concepts such as trust, norms, and networks that create optimal communication and participation of members of a community and ultimately guarantee their mutual benefits (Zheng, Yang, Nego, Liu, 2016). In other words, social capital is a set of active relationships between people, trust, mutual understanding, and shared values and behaviors that connect and enable collaboration between members of networks and human communities (Clopton, 2012). Lu, Zhao, and Weil (2019) showed in their research that social capital of nurses is one of the factors affecting their job satisfaction. The results of Eliacin et al.'s (2018) study showed a significant negative relationship between social capital and employee burnout. In a longitudinal study conducted by Freund (2015), the results showed that the amount of occupational participation the individual receives as well as the 
amount of commitment, whether emotional or professional, created over a period of time by this partnership is a predictor. It is strong and effective on job satisfaction. Abdolmaleki, Goodarzi, and Nourizadeh (2014) showed that there is a significant positive relationship between social capital and job satisfaction.

Another factor that may be contributing to job satisfaction is quality of life (Sule, Theadasare, Sonavane, Shah, 2017). Quality of life is a powerful force for guiding, maintaining, and promoting health and well-being in different societies and cultures (Schirda, Nicholas \& Prakash, 2015). The World Health Organization (2014) Four Dimensions of Physical, Mental, Social Relationships, and Living Environment). Is intended for quality of life; according to the World Health Organization (2014) definition of quality of life, people's understanding of their position in life, the cultural context and the value systems in which they live. Are related to their goals, expectations, standards and interests Quality of life is a broad concept that is influenced by health in a complex way. Physical, psychological status, degree of dependence, and social relations of the individual and his / her relationships with the environment (Meuleman, Chilcot, Dekker, Halbesma, 2017). Quality of life is an essential indicator of life and since Various aspects such as physiological aspects, function and existence of the individual are of particular importance (Monson, Caron, McCloskey, Brunet, 2017). The findings of Krishna research (2016) indicate that between quality of life and satisfaction There is a significant positive relationship between job and job. The purpose of the present study is to investigate the relationship between social capital and quality of life with teachers' job satisfaction.

\section{Methodology}

Objective: The purpose of this study was to investigate the relationship between social capital and quality of life with job satisfaction of teachers. Method: The present study was a descriptive correlational one in terms of purpose and method of data collection. The study population consisted of teachers in Tehran during 201920. The research population was teachers working in the educational districts of Tehran in 2019-20. The sample consisted of 180 individuals who were selected by multistage cluster random sampling. For this purpose, two districts 2 and 4 were randomly selected from the educational districts of Tehran and 7 schools were randomly selected from each district; one class was selected from each school and a total of 210 volunteers were recruited. Of these, 30 were excluded from the study due to incomplete questionnaires and not volunteering, and a total of 180 were selected as the sample size.

The process of conducting the research was to coordinate with the education of the districts, then with the school principals, and then with the teachers' program, which was completed on a specific day when all the teachers were in the secretariat meeting and all three questionnaires were completed in one session. . The research tool was Gannon (1981) Job Satisfaction Questionnaire consisting of 5 main components. A total of 20 closed-ended questions were designed for all of these components, rated on a 5 -point Likert scale ranging from very high (5) to very low (1). Gannon (1981) endorsed the 5 -factor structure of the questionnaire by factor analysis. The reliability coefficients of the subscales were also calculated between 0.74 and 0.87 . In Tafreshi (2018) version 20 questions were investigated which confirmed the face and structural validity of the tool and its reliability was reported higher than 0.70 by Cronbach's alpha method. In the present study, the total reliability coefficient of the questionnaire was 0.88 .

Quality of Life Scale: Quality of life data were collected using the World Health Organization's 26-question quality of life questionnaire. Since 1996, the validity and reliability of this questionnaire has been examined by the World Health Organization in different countries and cultures. Bonomy declared the internal reliability of the test to be 0.95 in his studies, and in 2000, the questionnaire was designed and translated simultaneously in 15 countries. Standardization, translation and psychometric evaluation of the Iranian version of this questionnaire was performed by Nejat et al in 2005. Cronbach's alpha correlation coefficients were above 0.7 in all domains and the questionnaire was translated twice into Persian for content validity, then experimental study. Its face validity was confirmed with high certainty (Nejat, Montazeri, Holakouee Naeini, Mohammad, 
2005). The questionnaire consists of 26 questions and is scored on a Likert scale. Not at all equal to one and very much equal to 5 . In the present study, the total reliability coefficient of the questionnaire was 0.81 .

Social Capital Questionnaire: This questionnaire was developed by Nahapiet and Ghoshal (1998) in 28 questions. The questionnaire has three structural, relational, and cognitive scales that examine components such as subscales of networks, trust, collaboration, mutual understanding, relationships, values, commitment. This questionnaire is based on a five-point Likert scale. (I strongly agree $=5$, I agree $=4$, I don't think $=3$, I disagree $=2$ and I strongly disagree $=1)$. Nahapiet and Ghoshal (1998) reported reliability and validity of this questionnaire. The reliability coefficient of the Persian version of this questionnaire was assessed by Cronbach's alpha method and calculated as 0.93 (Ghulich Lee \& Meshbeki, 2006). Also, Onogh Naz (2005) in the study of Cronbach's alpha coefficient obtained 0.91 for all three components and confirmed its validity by factor analysis. In the present study, the total reliability coefficient of the questionnaire was 0.74 and the reliability of the sub-variables was 0.84 and 0.68 , respectively.

Data were analyzed by multivariate and univariate regression methods after entering SPSS-25 software.

\section{Findings}

Subjects were 180 teachers whose frequency and percentage of demographic characteristics were presented in Table 1 by education, number of children and age range.

Table 1. Frequency and percentage of teachers' demographic characteristics

\begin{tabular}{cccc}
\hline & Levels & Abundance & Frequency \\
\hline Variables & Associate & 36 & 20 \\
\hline Education & Bachelor & 93 & $51 / 66$ \\
\hline & Masters & 51 & $28 / 33$ \\
\hline Gender & Man & 101 & $56 / 11$ \\
\hline Age range & Female & 79 & $43 / 89$ \\
\hline & $21-30$ Years & 24 & $43 / 33$ \\
\hline & $31-40$ Years & 83 & $31 / 11$ \\
\hline & $41-50$ Years & 56 & $9 / 44$
\end{tabular}

According to the results of Table 1, most of the teachers had undergraduate education (93 persons (51.66\%)), men (101 persons (56.11\%)) and age of 40-31 years (83 persons (46.11\%)). Table 2 presents the mean, standard deviation and Pearson correlation coefficients of quality of life, psychological capital, and job satisfaction among teachers. 
Table 2. Descriptive findings of quality of life variables of social capital and job satisfaction in teachers

\begin{tabular}{|c|c|c|c|c|c|c|c|}
\hline Variables & Average & $\begin{array}{c}\text { The } \\
\text { standard } \\
\text { deviation }\end{array}$ & 1 & 2 & 3 & 4 & \\
\hline Quality of life & $71 / 36$ & $7 / 87$ & & & & & \\
\hline Structural capital & $16 / 54$ & $3 / 78$ & $0 / 24^{* *}$ & & & & \\
\hline $\begin{array}{l}\text { Communication } \\
\text { capital }\end{array}$ & $15 / 59$ & $3 / 55$ & $0 / 19^{*}$ & $0 / 35^{* *}$ & & & \\
\hline Social capital & $15 / 66$ & $3 / 53$ & $0 / 17^{*}$ & $0 / 30^{* *}$ & $0 / 34^{* *}$ & & \\
\hline Cognitive Capital & $17 / 04$ & $3 / 36$ & $0 / 10$ & $0 / 43^{* *}$ & $0 / 32^{* *}$ & $0 / 39^{* *}$ & \\
\hline Job Satisfaction & $58 / 62$ & $7 / 19$ & $0 / 49^{* *}$ & $0 / 36^{* *}$ & $0 / 30^{* *}$ & $0 / 44^{* *}$ & $0 / 51^{* *}$ \\
\hline
\end{tabular}

According to the results of Table 2, structural capital $(r=0.36)$, communication capital $(r=0.30)$ and cognitive capital $(r=0.37)$ and social capital $(r=0.34)$ and quality of life $(r=0.34) . R=0.49)$ There was a significant positive relationship with teachers' job satisfaction $(\mathrm{P}<0.01)$. According to the results of Kolmogorov-Smirnov test, the assumption of normality of all variables was confirmed ( $>>0.05)$. Also, the variance inflation factor of the predictor variables ranged from 1.26 to 1.85 , so the multiple linear assumption is rejected because it is lower than 10. In addition, the camera-Watson value for the criterion variable was 1.79 , so the correlation of the residuals assumed to be in the range of 1.5 to 2.5 is rejected. Consequently, there are requirements for using multiple linear regression analysis. Multiple regression results for predicting job satisfaction based on social capital and quality of life in teachers are presented in Tables 3 and 4.

Table3. Multiple regression summaries for predicting teachers' job satisfaction

\begin{tabular}{cccccccc}
\hline Model & $\begin{array}{c}\text { The sum of } \\
\text { the } \\
\text { squares }\end{array}$ & $\begin{array}{c}\text { Degrees of } \\
\text { freedom }\end{array}$ & $\begin{array}{c}\text { Mean } \\
\text { squares }\end{array}$ & R & $\mathbf{R}^{2}$ & F & P-value \\
\hline regression & $1075 / 19$ & 4 & $268 / 76$ & $0 / 69$ & $0 / 48$ & $22 / 43$ & $0 / 001$ \\
\hline left over & $2098 / 23$ & 175 & $11 / 98$ & & & & \\
\hline Total & $3173 / 42$ & 179 & & & & \\
\hline
\end{tabular}

Table 4. Multiple regression coefficients for predicting teachers' job satisfaction

\begin{tabular}{ccccc}
\hline Variables & $\begin{array}{c}\text { Non-standard } \\
\text { coefficients }\end{array}$ & $\begin{array}{c}\text { Standard } \\
\text { coefficients }\end{array}$ & T statistics & P-value \\
\hline Quality of Life & $0 / 44$ & $0 / 47$ & $4 / 03$ & $0 / 001$ \\
\hline Structural capital & $0 / 34$ & $0 / 30$ & $3 / 42$ & $0 / 002$ \\
\hline $\begin{array}{c}\text { Communication } \\
\text { capital }\end{array}$ & $0 / 29$ & $0 / 25$ & $2 / 36$ & $0 / 01$ \\
\hline Cognitive Capital & $0 / 17$ & $0 / 14$ & $2 / 08$ & $0 / 03$ \\
\hline
\end{tabular}

According to the results of Table 3 , the prediction model of job satisfaction based on social capital and quality of life is confirmed ( $\mathrm{F}=22.43, \mathrm{P}<0.001)$ and predictor variables were able to predict $48 \%$ of teachers' job satisfaction changes. . According to the results of Table 4, quality of life has a direct impact on job satisfaction and structural capital, communication capital and cognitive capital have a direct impact on job satisfaction.

\section{Discussion}

Given the role and importance of quality of life and social capital in teachers' lives, this study aimed to predict job satisfaction based on social capital and quality of life in teachers. Findings showed that structural capital, communication capital and cognitive capital had a positive significant relationship with job satisfaction in teachers. This finding is in line with the findings of Lu, Zhao and Weil (2019), Abdolmaleki, Goodarzi and Nourizadeh (2014) and Freund (2015). For example, Lu, Zhao, and Weil (2019) found in their research that social capital of nurses is one of the factors affecting their job satisfaction. 
In explaining the results, it can be said that inclusive, dynamic and influential institutional education is the overarching ethical, political, economic, religious, legal, social and cultural behavior and norms of the community and the nature of its activities and goals, Promoting the spirit of creativity, flourishing and emerging talents, raising the level of public and specialized awareness and defining a strategy for achieving excellence, development, prosperity and growth (Shirvani Shiri, Norouzi, and Nematollahi, 2019). Teachers in schools, training centers and universities play a vital role in the social and economic development of a society, and their job satisfaction is a measure of organizational success and is often one of the factors contributing to the successful teaching and motivation of students, Is. However, depending on the nature of the teachers' job, their job satisfaction may vary, as it is influenced by several factors, including social capital. In general, the amount of social capital in any group or community reflects how much people trust each other (Halevy, Halali \& Cohen, 2019). Also, an acceptable level of social capital facilitates social action, so that in times of crisis social capital can be used as the primary source of problem solving and modification of existing processes to solve problems. What concerns social capital and its meaning is investing in social relationships as well as enhancing, expanding and sharing resources in or through relationships to facilitate collective action and the development of trust and debt in society. On the contrary, social relations are the main pillar of social capital. Therefore, if teachers are successful in interacting with other members of the school and students, they will have higher job satisfaction.

The findings also showed that there was a significant positive relationship between quality of life and job satisfaction in teachers. This finding was in line with the findings of the research findings of Krishna (2016), Lee, Beck \& Chan (2015), Bhatnagar \& Soni (2015), Asadi, Niazmand and Maleki Ziabari (2018) and Bakhshi and Kalantari (2016). This finding can be explained in the context of Herzberg's two-factor theory. Herzberg refers to physical needs and psychological needs, which operate on two different principles: physical needs act to avoid pain and discomfort, and factors that affect these needs. But it cannot be pleasing. In her studies, Herzberg found that job satisfaction and dissatisfaction factors could be studied separately. He named the factors that lead to employees' job satisfaction as "motivational" and the factors that caused Cochin dissatisfaction as "retention factors" or "two health factors". He concludes that if such needs are met, they are said to be satisfied with their work, and if not satisfied, they are dissatisfied with their organization and work. By satisfying these needs, the organization can reduce their dissatisfaction and even eliminate it (Lee, Beck \& \& Chan, 2015).

In addition, the findings showed that social capital and quality of life had a significant role in predicting teachers' job satisfaction. Given that social capital and quality of life are influential factors in job satisfaction, education officials can take an important step toward improving this factor by providing them with the opportunities to work and support them. It is therefore advisable for managers and education authorities to provide them with access to information, design and planning areas, and the authority to make decisions in the field of staffing so they can develop their capabilities and also advise managers. Employing employees with independence and freedom so that they can realize their potential and innovate in their work. In this regard, social capital as an intangible asset in organizations, especially schools through interpersonal relationships between teachers and administrators, is based on trust and cooperation and increased group cohesion, and it is suggested to increase teachers' job satisfaction. To raise awareness about the role and position of social capital in schools. The most important limitations include limiting the research community to teachers in Tehran, using self-report tools to collect data and not controlling for confounding variables such as the willingness and motivation of some individuals and the low interest and motivation of others. Given the limitations, it is recommended that this study be conducted on other occupations or teachers in other cities and compare the results with those of this study. It is also suggested that in future research some of the confounding variables such as age and education of the control will be used and the interview will be used for data collection. It is suggested to increase the job satisfaction and quality of life with the aim and plan of doing research activities. 


\section{References}

Abdolmaleki H, Goodarzi M, Nourizadeh A. (2014). The relationship between social capital and job satisfaction of physical education teachers. Social Capital Management, 1 (1): 80-65.

Asadi P, Niazmand F, Maleki Ziabari M. (2018). The Relationship between Quality of Work Life and Organizational Commitment in Emergency and Emergency Management Center Personnel. Journal of Guilan University of Medical Sciences, (106): 17-22.

Bakhshi E, Kalantari R. (1395). Assessment of quality of work life and its relation with job performance in health care workers. Journal of Occupational Health Engineering, 3 (4): 37-31.

Bellamy N D, Wang M Q, McGee L A, Liu J S. (2019). Crisis-counselor perceptions of job training, stress, and satisfaction during disaster recovery. Psychological Trauma: Theory, Research, Practice, and Policy, 11(1): 19-27.

Bhatnagar T, Soni H. (2015). Impact of quality of work life on job satisfaction of school teachers in Udaipur City. Journal of Business and Management, 17(3):10-15.

Burić I, Penezić Z, Sorić I. (2017). Regulating emotions in the teacher's workplace: Development and initial validation of the Teacher Emotion-Regulation Scale. International Journal of Stress Management, 24(3): 217-246.

Cheng C, Wang H y, Sigerson L, Chau C l. (2019). Do the socially rich get richer? A nuanced perspective on social network site use and online social capital accrual. Psychological Bulletin, 145(7):734-764.

Clopton A W. (2012). Social capital, gender, and the student athlete. Group Dynamics: Theory, Research, and Practice, 16(4), $272-288$.

Collie R J, Shapka J D, Perry N E. (2012). School climate and social-emotional learning: Predicting teacher stress, job satisfaction, and teaching efficacy. Journal of Educational Psychology, 104(4): 1189-1204.

Demerouti E, Bakker A B, Leiter M. (2014). Burnout and job performance: The moderating role of selection, optimization, and compensation strategies. Journal of Occupational Health Psychology, 19(1): 96-107.

Dicke T, Marsh H W, Parker P D, Guo J. (2019). Job satisfaction of teachers and their principals in relation to climate and student achievement. Journal of Educational Psychology. Advance online publication.

Eliacin J, Flanagan M, Monroe DeVita M, Wasmuth S, et all. (2018). Social capital and burnout among mental healthcare providers. Journal of Mental Health, 27(5): 388-394.

Freund A. (2015). Do Multiple Commitments Predict Job Satisfaction in Third Sector Organizations? A Longitudinal Analysis. Humanistic Management Network, Research Paper Series .26(15): 405-415.

Gannon M J. (1981). Paine 1974 "Unity of command and job at-titudes of managers in a bureaucratic organization. Journal of Applied Psychology, (59): 392-394.

Ghulich Lee B, Meshbeki A. (2006). The Role of Social Capital in Creating Organizational Intellectual Capital (A Study of Two Iranian Automobile Companies). Management Knowledge Quarterly, (75): 125-147.

Hagman G. (1992). Industrial and Organizational Psychology: Motivation and Transition Management. Translated by Ali Mohammad Goodarzi (2016). Tehran: Rasa Cultural Services Publishing.

Halevy N, Halali E, Cohen T R. (2019). Brokering orientations and social capital: Influencing others' relationships shapes status and trust. Journal of Personality and Social Psychology. Advance online publication.

Hardin E E, Donaldson J R. (2014). Predicting job satisfaction: A new perspective on person-environment fit. Journal of Counseling Psychology, 61(4): 634-640

Judge T A, Weiss H M, Kammeyer-Mueller J D, Hulin C L. (2017). Job attitudes, job satisfaction, and job affect: A century of continuity and of change. Journal of Applied Psychology, 102(3): 356-374.

Kabat-Farr D, Cortina L M, Marchiondo L A. (2018). The emotional aftermath of incivility: Anger, guilt, and the role of organizational commitment. International Journal of Stress Management, 25(2): 109-128.

Krishna G S. (2016). A Study on Enhancing the Quality of Life and Job Satisfaction among Transgender in Southern Districts of Tamilnadu. Asian Journal of Research in Social Sciences and Humanities, 6(8): 1555.

Lee J, Back K, Chan E. (2015), "Quality of work life and job satisfaction among frontline hotel employees", International Journal of Contemporary Hospitality Management, 27(5): 768-789

Lu H, Zhao Y, While A. (2019). Job satisfaction among hospital nurses: A literature review. International Journal of Nursing Studies, (94): 21-31.

Meuleman Y, Chilcot J, Dekker F W, Halbesma N. (2017). Health-related quality of life trajectories during predialysis care and associated illness perceptions. Health Psychology, 36(11): 1083-1091.

Monson E, Caron J, McCloskey K, Brunet A. (2017). Longitudinal analysis of quality of life across the trauma spectrum. Psychological Trauma: Theory, Research, Practice, and Policy, 9(5): 605-612.

Nahapiet J, Ghoshal S. (1998) "Social Capital, Intellectual capital \& the organizational advantage"; Academy of management Review, 23(2): 242-260.

Nejat S, Montazeri A, Holakouee Naeini C, Mohammad K. (2005). Standardization of the World Health Organization Quality of Life Questionnaire (WHOQOL-BREF): Iranian species translation and psychometrics. Journal of the School of Health and Health Research Institute, 4 (4): 12-1. 
Onogh Naz M. (2015). Investigating the Relationship between Social Capital and Quality of Life. M.Sc., University of Tehran.

Rezaei Sharif A, Karimianpour Gh, Moradi Sh, Karimianpour E. (2018). Investigating the Relationship between Work Ethics and Commitment to Change with Mediating Job Desire Among Elementary Teachers. Journal of Occupational and Organizational Counseling, 10 (34): 79-64.

Robbins S P. (2001). organizational behavior. Parsaian, Ali and Arabi, Mohammad (2015). Tehran: Office of Cultural Research Publications.

Schaumberg R L, Flynn F J. (2017). Clarifying the link between job satisfaction and absenteeism: The role of guilt proneness. Journal of Applied Psychology, 102(6): 982-992.

Schirda B, Nicholas J A, Prakash R S. (2015). Examining trait mindfulness, emotion dysregulation, and quality of life in multiple sclerosis. Health Psychology, 34(11): 1107-1115.

Shirvani Shiri A, Norouzi R A, Nematollahi S. (2019). Analyzing the question of the relationship between the learner and the teacher with an emphasis on new educational approaches. Journal of Education Research, (19): 30-46.

Sule R, Theadasare H, Sonavane S, Shah N. (2017). A Study of Job Satisfaction, Job Stress and Quality of Life in Auxiliary Health Care Workers of a Public Tertiary General Hospital. Journal of Psychosocial Rehabilitation and Mental Health, 4(1): 23-27.

Tafreshi, Ali. (1397). Predicting Job Satisfaction Based on Quality of Work Life and Quality of Life of Bank Mellat Staff. M.Sc., Islamic Azad University, Tehran Branch.

Van den Bergh M, Schmittmann V D, Vermunt J K. (2017). Building latent class trees, with an application to a study of social capital. Methodology: European Journal of Research Methods for the Behavioral and Social Sciences, 13(1):13-22.

World Health Organization. (2014). Facts on ageing and the life course. World Health Organization, Geneva, Switzerland Retrieved from (http://www. who. int/features/fact files/ageing/en/).

Zheng X, Yang J, Ngo H Y, Liu X Y. (2016). Workplace ostracism and its negative outcomes: Psychological capital as a moderator. Journal of Personnel Psychology, 15(4): 143-151. 